\title{
AGRONEGÓCIO E NOVAS REGIONALIZAÇÕES NO BRASIL
}

\author{
DENISE ELIAS
}

R E S U M O As transformaçôes ocorridas na atividade agropecuária brasileira nas últimas cinco décadas têm profundos impactos sobre a (re)organização do território brasileiro, resultando em novos arranjos territoriais. Entre esses, destacam-se os inerentes ao agronegócio globalizado, áreas escolhidas para receber os mais expressivos investimentos produtivos do setor, representando suas áreas mais competitivas, as quais denominamos Regiōes Produtivas Agricolas (RPAs). Os principais objetivos desse texto são: debater a noção de RPA; apresentar os elementos de identificação e caracterização da mencionada regiāo; aperfeiçoar o caminho analítico que vem sendo trilhado e incrementar a noção no contexto dos estudos geográficos, na perspectiva de uma possivel consolidação conceitual dessa ideia.

P A L A V R A S - C H A V E Agronegócio; urbanização dispersa; reestruturação urbana e regional.

\section{INTRODUÇÃ O'}

O presente texto faz parte da linha de pesquisa Agronegócio e Novas Dinâmicas Socioespaciais, com a qual tenho trabalhado desde o início da década de 1990, processo reforçado com a criação do Grupo de Pesquisa Globalização, Agricultura e Urbanização (GLOBAU), certificado pelo CNPq. Essa linha de pesquisa tem como objetivo central a análise das dinâmicas de produção e reprodução dos espaços agrícolas e urbanos associados ao processo de reestruturação produtiva da agropecuária brasileira. Sua meta principal é avançar na compreensão da (re)estruturação urbana e regional resultante da difusão do modelo econômico e social de produção agropecuária preconizado com a globalização.

Como tenho defendido, as transformações ocorridas na atividade agropecuária no Brasil, nas últimas cinco décadas, têm profundos impactos sobre a (re)organização do território brasileiro, resultando em novos arranjos territoriais. Entre esses, destacarei aqui o que tenho chamado, nos últimos anos, de Regiōes Produtivas Agrícolas (RPAs).

As RPAs são os novos arranjos territoriais produtivos agrícolas, os territórios das redes agroindustriais, escolhidos para receber os mais expressivos investimentos produtivos inerentes ao agronegócio globalizado, representando suas áreas mais competitivas. Nelas encontram-se partes dos circuitos espaciais da produção e círculos de cooperação de importantes commodities agrícolas, evidenciando a dinâmica territorial do agronegócio.

Nas RPAs, as grandes corporações concernentes às redes agroindustriais são os maiores agentes produtores do espaço agrário e urbano. Como consequência de tais processos, intensificam-se as relações campo-cidade e a urbanização, uma vez que as redes agroindustriais necessitam também de processos que se dão no espaço urbano próximo às áreas de produção agrícola e agroindustrial, incrementando o crescimento de cidades totalmente funcionais ao agronegócio, as quais passam a ter novas funções, tal como a de gestão desse

1 Agradeço ao CNPq pelo financiamento de algumas das minhas pesquisas nos últimos anos. Agradeço, também, ao professor Dr. Renato Pequeno, do Departamento de Arquitetura e Urbanismo da Universidade Federal do Ceará (UFC), pela leitura cuidadosa e sugestões. Não the cabe, no entanto, nenhuma responsabilidade por qualquer equívoco aqui encontrado ou por alguns caminhos teóricoconceituais adotados. 
agronegócio globalizado. Processa-se, em última instância, a produção de territórios especializados e corporativos inerentes a esse agronegócio.

O estudo das Regiões Produtivas Agrícolas não se limita a um campo de estudo da Geografia, mas demanda e perpassa vários campos, tais como da Geografia Agrária, da Geografia Econômica, da Geografia Urbana, da Geografia Regional, Economia Política, assim como da Economia Espacial, Sociologia Rural, entre outros. Consequentemente, a realização de estudos e pesquisas sobre as RPAs torna-se bastante complexa. Assim, há muito trabalho pela frente para podermos, de fato, avançar no caminho da construção teórico-conceitual para a elaboração do conceito e, especialmente, da metodologia visando à operacionalização de pesquisas com tais objetivos.

Para finalizar esta introdução, destaco que para o estudo das Regiōes Produtivas Agrícolas valorizo, de um lado, o diálogo com aqueles que estudam o espaço agrário brasileiro, e também com aqueles que estudam os espaços urbanos não metropolitanos e os processos de (re)estruturação urbana e regional, reconhecendo as respectivas contribuiçóes para o desenvolvimento de noçóes, teorias e conceitos sobre os processos e dinâmicas socioespaciais emergentes no território brasileiro.

Por outro lado, é importante reconhecer a existência de especificidades nas formas de produção e apropriação do espaço agrícola e urbano nas diferentes Regiōes Produtivas Agrícolas, importantes nós, pontos ou manchas de redes agroindustriais com circuitos espaciais de produção globalizados, com poder de promover significativas (re)estruturações urbanas e regionais. Todas merecem atenção em um país de grandes dimensões e diversidade regional como o Brasil.

Dessa maneira, os estudos que alicerçam este texto refletem um caminho que vem sendo trilhado e, ao mesmo tempo, mostra haver muito ainda a ser feito para podermos, efetivamente, conhecer melhor as mudanças em curso nos papéis desempenhados pelos espaços agrícolas, urbanos e regionais componentes das redes agroindustriais, à medida que se amplia o movimento de ocupação do território brasileiro de forma mais articulada à economia internacional.

A utilização desse recorte espacial baseado nas Regiōes Produtivas Agrícolas para o estudo do território nacional pode auxiliar a melhor entender a divisão territorial do trabalho hoje vigente no país, pois leva em conta o impacto da reestruturação produtiva da agropecuária e a organização das redes agroindustriais. Portanto, considera a base da organização de uma parte significativa do território brasileiro atual, resultado da herança histórica e das metamorfoses do presente, marcado pela velocidade das inovações.

2 Sobre o tema pode ser visto, em especial, Elias (2006a, b, 2008, 2010).

\section{REGIÕES PRODUTIVAS AGRÍCOLAS: ${ }^{2}$ CARACTERÍSTICAS E ELEMENTOS DE ARGUMENTAÇÃO}

Como tese central, segundo tenho defendido, as transformações ocorridas na atividade agropecuária no Brasil, nas últimas cinco décadas, exercem profundos impactos sobre a (re)organização do território brasileiro, resultando em novos arranjos territoriais, entre os quais o ora denominado Regiōes Produtivas Agrícolas (RPAs).

A reestruturação produtiva da agropecuária, entendida como processo promotor de transformações nos elementos técnicos e sociais da estrutura agrária (especialmente alterando a base técnica da produção, as relações sociais de produção e a estrutura fundiária), que atinge tanto a base técnica quanto a econômica e social do setor, tem profundos 
impactos sobre os espaços agrícolas e urbanos. Estes passam, então, por um processo acelerado de reorganização, com incremento da urbanizaçãoo e de processos de (re)estruturação urbana e regional, com a formação ou consolidação de Regiōes Produtivas Agrícolas, por todo o Brasil.

As RPAs são os novos arranjos territoriais produtivos totalmente associados ao agronegócio globalizado e, assim, inerentes às redes agroindustriais. ${ }^{3}$ Dessa forma, são compostas tanto pelos espaços agrícolas como pelos urbanos escolhidos para receber os mais sólidos investimentos privados, formando os focos dinâmicos da economia agrária, ou seja, são áreas de difusão de vários ramos do agronegócio, palco de circuitos superiores do agronegócio globalizado.

As RPAs compõem lugares propícios ao exercício dos capitais hegemônicos porquanto apresentam muitas novas possibilidades para a acumulação ampliada no setor, cada vez menos resistente às ingerências exógenas e aos novos signos do período histórico atual. Nas RPAs estão partes dos circuitos espaciais da produção e círculos de cooperação (Santos, 1988) de importantes commodities. Logo, encontram-se sob o comando de grandes empresas, nacionais e multinacionais, as mesmas que estão à frente das redes agroindustriais globalizadas, representando lugares funcionais dessas.

Como o agronegócio globalizado se realiza totalmente a partir da dialética entre a ordem global e a ordem local, as RPAs estão conectadas diretamente aos centros de poder e consumo em nível mundial e, assim, as escalas locais e regionais articulam-se permanentemente com a internacional e o território organiza-se com base em imposições do mercado, comandado por grandes empresas nacionais e multinacionais. Isso significa que nas RPAs temos novos espaços de fluxos rápidos inerentes às redes agroindustriais, nas quais as verticalidades têm predominância sobre as horizontalidades. ${ }^{4}$ Mas, em contrapartida, as horizontalidades são extremamente difundidas, como evidenciado pela expansão das atividades econômicas, pelo aumento da população e do mercado de trabalho, pela chegada dos novos agentes econômicos representativos das atividades modernas etc.

Nas RPAs a solidariedade organizacional imposta pelas empresas hegemônicas do agronegócio é preponderante sobre a solidariedade orgânica, ${ }^{5}$ localmente e historicamente tecida, que fica extremamente comprometida. Processa-se, dessa forma e em última instância, a produção de territórios especializados e corporativos inerentes aos diversos circuitos da economia agrária e agroindustrial, notadamente relacionados ao circuito superior do agronegócio globalizado. Adaptando noções elaboradas por Milton Santos, aqui no caso de pontos luminosos, diria que as RPAs são os pontos luminosos do espaço agrário brasileiro.

Contudo, o fato de os circuitos superiores do agronegócio serem hegemônicos nas RPAs não elimina a existência de superposições de divisões territoriais do trabalho particulares, responsáveis pela formação de vários circuitos da economia agrária, tais como os formados a partir da agricultura camponesa não integrada ao agronegócio. O que nos dá que as RPAs são também o lugar de conflitos de várias naturezas.

Diante das demandas da produção agropecuária globalizada, as RPAs compõem-se tanto por modernos espaços agrícolas, extremamente racionalizados, quanto por espaços urbanos não metropolitanos (especialmente cidades pequenas, mas também cidades de porte médio). Esses formam nós, pontos ou manchas de redes agroindustriais e são perpassados pelos circuitos espaciais locais e regionais daquelas. Isso ocorre seja nos lugares de reserva, ${ }^{6}$ inseridos mais recentemente à agropecuária globalizada, passíveis de serem exemplificados, principalmente, a partir de casos nas Regiões Norte, Nordeste e Centro-
3 As redes agroindustriais associam todas as atividades inerentes ao agronegócio, seja a agropecuária propriamente dita, sejam as atividades que antecedem essa produção e lhe são fundamentais (pesquisa agropecuária, produção de máquinas agrícolas, sementes selecionadas, fertilizantes etc.), sejam as atividades de transformação industria cuja matéria-prima provém da atividade agropecuária, seja de distribuição dos alimentos prontos etc.

4 Sobre verticalidades e horizontalidades ver Santos (1996).

5 Sobre solidariedades orgânica e organizacional ver Santos (1996).

6 Mais comumente chamados de fronteira agrícola, aos quais preferimos chamar de lugares de reserva, baseando-nos na noção utilizada por Santos (1993). 
Oeste, seja nas regiôes agrícolas que há mais tempo participam do circuito superior da economia agrária, fortemente concentradas nas Regióes Sudeste e Sul.

Entre os resultados da formação das RPAs, surge um aumento da dialética na organização do espaço brasileiro, denotando significativas fragmentações deste espaço, com permanentes processos de (re)estruturação urbana e regional. Dessa maneira, a reestruturação produtiva da agropecuária tem profundos impactos sobre os espaços agrícolas e urbanos não metropolitanos, ainda em processo acelerado de reorganização, compondo novos arranjos territoriais fortemente alicerçados no agronegócio globalizado. Tal realidade acirra a refuncionalização desses arranjos e leva à difusão de especializações territoriais produtivas, denotando-se inúmeras seletividades, seja da organização da produção, seja da dinâmica dos respectivos espaços. Do mesmo modo, as RPAs são os novos espaços de exclusão e de toda sorte de desigualdades socioespaciais.

É fundamental, nesse ponto, destacar o seguinte: as RPAs em nada lembram a forma mais clássica inerente ao conceito de região, à forma como foi por longo período entendida e trabalhada pela Geografia. A RPA em nada lembra a categoria de região que foi dominante na Geografia por longo tempo, ou seja, não se assemelha à categoria região de fases históricas precedentes. Na noção clássica de região essa parecia dotada de certa autonomia, independente das relaçóes do país como um todo e com o sistema mundial, assim como marcada por certa imobilidade dos fatores de produção, muito fechada em si mesma. Tais características em nada lembram as RPAs.

Portanto, as RPAs devem ser estudadas como lugares funcionais de circuitos espaciais da produção e círculos de cooperação da produção de importantes commodities, cada vez menos resistente às ingerências exógenas e aos novos signos do período histórico atual, comandado por algumas empresas hegemônicas do setor, tornando-se lugares do fazer do agronegócio globalizado. Assim, na definição das RPAs, estamos longe daquela solidariedade orgânica que era o próprio cerne da definição do fenômeno regional.

As mencionadas regiōes são frações do espaço total das redes agroindustriais globalizadas, cada vez mais abertas às influências exógenas e aos novos signos do período atual. Existem porque sobre elas se impõem arranjos organizacionais, criadores de coesão organizacional baseada em racionalidades de origens distantes, mas que se tornam o fundamento da existência e da definição desses subespaços. Diante disso, a RPA é resultado do impacto das forças externas/modernizantes e a capacidade de suas virtualidades, lugar funcional das redes agroindustriais globalizadas. Como objeto e sujeito da economia globalizada, é um espaço que nada mais tem de autônomo, não se fechando sobre si mesmo, de forma independente do restante do mundo, com o qual interage permanentemente para a renovação tecnológica, para a complementação da produção e, em última instância, para a acumulação ampliada do capital do agronegócio.

Como já evidenciei em outros momentos, com o advento da globalização, inúmeros pesquisadores têm afirmado que as características desse novo período histórico apagaram o espaço e que a expansão do capital e da tecnologia teria eliminado as diferenciações regionais e, até mesmo, proibido se prosseguir pensando que a região existe. Vou em sentido inverso a essa compreensão. Concordo com Santos (1994b; 1988), para quem, muito ao contrário, nunca os lugares foram táo distintos uns dos outros, porquanto, o tempo acelerado, ao acentuar a diferenciação dos eventos, aumenta a diferenciação dos lugares.

Diria, então, que as RPAs ajudam a pensar sobre essas questóes, pois também apresentam muitas diferenças entre si, sobretudo porque cada commodity possui suas 
próprias exigências de insumos químicos, serviços, força de trabalho, tecnologia, capital, maquinário etc. o que resulta em arranjos territoriais produtivos distintos. Por exemplo, nas RPAs comandadas pela produção e transformação da soja, o mercado de trabalho agrícola formal não tem o mesmo crescimento das RPAs comandadas pela produção de frutas tropicais: a primeira tem seu processo produtivo quase totalmente mecanizado, a segunda demanda maior quantidade de mão de obra, especialmente em alguns momentos do processo de produção.

\section{DelimitaÇÃo das RPAs}

Para chegar à delimitação espacial precisa de uma RPA é necessário cuidado, até porque, em fase da dinâmica dos processos adjacentes, essa delimitação sofre mudanças permanentemente. Mesmo que assim não fosse, é sempre difícil, no início de uma pesquisa sobre as RPAs, saber exatamente quais os limites a serem considerados para ela, até porque só os estudos e pesquisas sobre as regiões é que efetivamente mostrarão seu desenho preciso. Nesse ponto, destaco: a configuração das RPAs não respeita os limites político-administrativos oficiais e, assim, é bastante comum uma mesma RPA ser formada por municípios de diferentes Estados. Algumas dessas delimitações, muito embora não existam oficialmente, são reconhecidas pelas populações locais e empresas atuantes nas respectivas áreas.

Como exemplo desse processo, mencionamos uma pesquisa desenvolvida na Região Nordeste, relacionada ao estudo das áreas de difusão do agronegócio de soja e de fruticultura tropical. Essa pesquisa nos levou à conclusão de estarmos lidando com três principais RPAs. Uma composta, grosso modo, pelas microrregiôes do Baixo Jaguaribe (CE), Mossoró e Vale do Açu (ambas no RN), ${ }^{7}$ destaca-se pela produção de frutas tropicais, especialmente melão, banana e abacaxi, tem seu espaço comandado a partir de Mossoró, cidade de porte médio, a segunda mais importante do Estado do Rio Grande do Norte; ${ }^{8}$ uma segunda RPA formada pelas microrregiōes de Juazeiro (BA) e Petrolina (PE), nacionalmente conhecida por ser um dos primeiros vales úmidos do Nordeste ocupado pela produção intensiva de frutas tropicais, especialmente uva, é uma região comandada a partir da cidade de Petrolina; uma terceira Região Produtiva Agrícola composta pelas microrregiōes com destacada produção de soja, Alto Parnaíba Piauiense (PI), Barreiras (BA) e Gerais de Balsas (MA), comandadas, especialmente, por Barreiras, uma cidade de porte médio. ${ }^{9}$

Naturalmente, as RPAs abarcam somente uma parte dos circuitos espaciais da produção e dos círculos de cooperação, os circuitos locais e regionais. Os demais só podem ser visualizados ao se considerar todas as etapas do processo produtivo da commodity a ser estudada, pois muitos deles não se dão na RPA ou mesmo no país. Basta lembrarmos, por exemplo, que a maior parte das commodities tem como destino o mercado internacional. Portanto, as RPAs são um lugar funcional do agronegócio globalizado, meras regiōes do fazer, ${ }^{10}$ com pouquíssima ou nenhuma ingerência efetiva sobre as respectivas produções agrícolas e agroindustriais nelas ocorridas.

\section{Processos Inerentes À Difusão do Agronegócio}

São muitos os processos associados ao rearranjo do território nas áreas de difusão do agronegócio globalizado. Elencá-los é fundamental para a tarefa de melhor compreender a ocorrência do fenômeno principal em foco. Cito alguns dos mais importantes: a intensa
7 As microrregiões do IBGE não compõem, necessariamente, a melhor forma de delimitação das RPAs. Mas são, indubitavelmente, um bom começo para os estudos com tal objetivo. Uma referência também importante para iniciar uma pesquisa sobre uma RPA são os estudos da Regic, do IBGE (1993, 2009).

8 Sobre a cidade de Mossoró e sua respectiva região de influência de maneira geral, assim como sobre os papéis desempenhados por Mossoró inerentes ao consumo produtivo agrícola ver Elias e Pequeno (2010).

9 Somadas a terras em Tocantins, comporia o que alguns vêm chamando de Mapitoba, região a qual abarcaria terras no Maranhão, Piauí, Tocantins e Bahia. Sobre a referida pesquisa ver Elias e Pequeno (2006).

10 Sobre regiões do fazer e regiões do gerir ver Santos (1996, 2000). 
substituição dos sistemas técnicos agrícolas, que passam a ter alta densidade de capital e tecnologia; a significativa mudança das formas de uso e ocupação do espaço agrícola, com forte substituição da produção de alimentos pela produção de commodities, com a implantação de monoculturas, substituindo vocações naturais pelas imposições econômicas, difundindo especializações produtivas.

Os processos supracitados estão entre os que ajudam a evidenciar a refuncionalização do espaço agrícola, por meio do aumento da racionalização deste, uma vez que passa a ter forte densidade técnica e normativa, e já evidencia outro processo também bastante significativo associado, qual seja, o de destruição de saberes e fazeres historicamente construídos, porquanto, como a difusão do agronegócio não se dá sobre espaços desocupados, inviabiliza a atividade para milhares de pequenos agricultores, que viviam da subsistência ou da produção simples de mercadorias. Esses são expropriados ou expulsos, em grande parte, gerando muitos conflitos sociais.

A partir desse ponto, podemos destacar os processos incluídos entre os mais devastadores da reestruturação produtiva da agropecuária e da organização das redes agroindustriais, qual seja, o acirramento da privatização do acesso à terra e à água, dois dos fatores principais de produção para a agropecuária, não passíveis de serem reproduzidos ao livre arbítrio do homem, como outros. Naturalmente, tal processo está vinculado à territorialização do grande capital e à monopolização do território.

Ainda hoje o baixo preço da terra é um dos fatores atrativos das novas Regióes Produtivas Agrícolas. Entretanto, a intensificação do valor de troca em detrimento do valor de uso vem promovendo um crescimento geométrico do preço desta. Atualmente, embora tenha se instalado uma nova dinâmica do mercado de terras no que considero sejam os pontos luminosos do espaço agrário brasileiro, nos quais já se observa claramente a forte presença de especuladores, brasileiros e estrangeiros, algumas dessas áreas ainda possuem preços mais baixos do que as áreas onde a capitalização do campo é mais antiga e complexa. ${ }^{11}$

Esses processos levam ao aumento da concentração fundiária e êxodo rural, motivado trabalho de campo no oeste da Bahia e demais áreas dos cerrados nordestinos, conforme mencionado, a terra ficou muito cara e chegou a aumentar até setenta vezes desde a década de 1970 até meados da década de 2010. Da mesma forma, em algumas áreas o processo de regularização fundiária é bem mais recente. Merecem destaque as áreas do sul do Maranhão e do Piauí, onde a violência é a regra. No tocante a estas áreas, as narrativas quanto aos conflitos de terra e processos de grilagem foram recorrentes. pela expulsão e expropriação de uma série de pequenos agricultores, de parceiros, posseiros que não detinham a propriedade da terra. Imbricada a essa realidade, há a significativa mudança de parte das relações sociais de produção, com o incremento da formação de um mercado de trabalho agrícola formal, em parte composto por pequenos agricultores expulsos ou expropriados pela difusão do agronegócio. Dessa forma, parcela expressiva das relações de trabalho no espaço agrícola nas RPAs é dominada por relações assalariadas.

Ao mesmo tempo, observam-se movimentos migratórios descendentes (da cidade maior para a cidade menor) advindos de profissionais especializados para o agronegócio. Observa-se, também, o aumento da divisão social e territorial do trabalho agropecuário.

Outro processo bastante expressivo para compreendermos a organização das RPAs associa-se ao incremento das trocas verificadas entre os diferentes ramos do agronegócio e os demais setores da economia. Isso acontece pelo fato de o agronegócio globalizado não se dar sem uma série de diferentes insumos e implementos, assim como de inúmeros serviços especializados. Igualmente, as relações com o setor industrial são bastante incrementadas, seja porque esses fornecem uma série de máquinas e insumos demandados pela agropecuária, seja porque os frutos dessa atividade sofrem, em grande parte, algum processamento industrial, com vistas à produção de mercadorias padronizadas, com objetivo de agregar valor.

Alguns outros processos serão ressaltados nas seções a seguir, tais como o da intensificação de novas relações campo-cidade; do aumento da urbanização; da reestruturação urbana e regional. 


\section{NOVAS RELAÇÕES CAMPO-CIDADE E (RE)ESTRUTURAÇÃO URBANA E REGIONAL}

A reestruturação produtiva da agropecuária cria demandas até então inexistentes nas áreas de difusão do agronegócio. Tais demandas incrementam o crescimento de uma série de atividades comerciais e de serviços especializados. Dessa forma, a difusão do agronegócio não apenas amplia e reorganiza a produção material (agropecuária e industrial), como é determinante para a expansão quantitativa e qualitativa do comércio e dos serviços, especialmente dos ramos associados ao circuito superior da economia agrária. $\mathrm{O}$ crescimento do terciário se deve ainda ao crescimento da população e à revolução do consumo, este último erigido sob os auspícios do consumo de massa associado à existência individual e das famílias.

Assim, a produção agrícola e agroindustrial intensiva exige que os espaços urbanos próximos ao espaço agrícola racionalizado se adaptem para atender às suas principais demandas, em virtude de fornecerem parte dos aportes técnicos, financeiros, jurídicos, de mão de obra e de todos os demais produtos e serviços necessários à sua realização.

Nesse âmbito, citaria as casas de comércio de implementos agrícolas, sementes, grãos e fertilizantes; os escritórios de marketing e de consultoria contábil; os centros de pesquisa biotecnológica; as empresas de assistência técnica e de transportes de cargas; os serviços de especialista em engenharia genética, veterinária, administração, meteorologia, agronomia, economia, administração pública; os cursos técnicos de nível médio e os cursos superiores voltados ao agronegócio, entre tantas outras atividades.

Conforme evidenciado, os espaços urbanos próximos às áreas de difusão do agronegócio passam a ter novas funções inerentes às demandas desse. Essas podem ser observadas pela expansão do consumo produtivo agrícola (Santos, 1988; Elias, 2003a, b), aquele associado diretamente às demandas da produção. Como resultado, temos o crescimento da economia urbana, a revelar que os circuitos espaciais da produção e os círculos de cooperação do agronegócio se realizam totalmente em uníssono com o espaço urbano. Isso denota que a materialização das condiçôes gerais de reprodução do capital do agronegócio também se dá no espaço urbano, próximo e distante (Elias, 2006a, b, c, d). Dessa forma, os espaços urbanos das RPAs passam a se constituir como nós fundamentais na rede de relaçōes desse agronegócio, seja em termos demográficos, econômicos ou espaciais. ${ }^{12}$

Em virtude de cada commodity ter diferentes demandas de produtos e serviços, esses espaços urbanos são cada vez mais especializados. O consumo produtivo do agronegócio ressalta demandas heterogêneas segundo as necessidades de produção (agrícola ou agroindustrial) de cada produto, nas diferentes etapas do processo produtivo, diferenciando, muitas vezes, os ramos dos comércios e dos serviços associados à expansão desse consumo. Tal situação acontece, principalmente, porque o agronegócio tem o poder de impor especializaçôes territoriais cada vez mais profundas e, assim, criar muitos novos fluxos, materiais e de informação, próximos ou não, cujos circuitos espaciais da produção e círculos de cooperação buscam nexos distantes.

As diferentes especializações e funções exercidas por cada um desses espaços urbanos não metropolitanos podem mais facilmente ser percebidas durante as diferentes etapas do processo produtivo, como na safra e na entressafra. É no período de safra das principais culturas que podemos distinguir com maior nitidez a especialização das áreas de difusão do agronegócio. Esse é o momento mais dinâmico nas várias Regiōes Produtivas Agrícolas, afetando todos os setores econômicos. Um exemplo marcante é o funcionamento
12 Já realizamos alguns estudos sobre o consumo produtivo agrícola. Ver, por exemplo, Elias (2003) e Elias e Pequeno (2010). 
ininterrupto, durante vinte e quatro horas, de muitas das agroindústrias cuja manutenção se dá apenas durante a entressafra. É também no período da colheita que aumenta o número de empregos agrícolas temporários, especialmente para a colheita das culturas nas quais ainda não predomina a mecanização na realização desta etapa do processo produtivo, como a produção de frutas (uva, banana, melão, entre outras).

$\mathrm{O}$ incremento das relações entre os diferentes setores econômicos associados à organização das redes agroindustriais é um importante caminho para a compreensão de como se processa uma série de novas relações entre o campo e a cidade. Quanto mais dinâmica a reestruturação produtiva da agropecuária, quanto mais complexa a formação das redes agroindustriais e quanto mais globalizados seus circuitos espaciais de produção e seus círculos de cooperação, mais complexas se tornam as relações campo-cidade. Consequentemente, cria-se uma gama de novas relações sobre o território. Essas relações ajudam a transformar radicalmente as clássicas relações campo-cidade e levam esses dois espaços a emitir e a receber larga quantidade de fluxos de matéria e informação, de várias naturezas e magnitudes. O resultado é uma total reorganização do território brasileiro, agrícola, urbano e regional.

Nas RPAs a oposição clássica entre a cidade e o campo torna-se bastante relativizada e a noção de complementaridade ganha mais força e importância. Tudo isso nos leva a dizer que as próprias contradiçôes do desenvolvimento do capitalismo estão soldando a união contraditória que separou no início da sua expansão: a indústria e a agricultura, a cidade e o campo.

Essas dinâmicas socioespaciais culminam, entre outros, em processos de (re)estruturação urbana e regional, com a organização de novos arranjos territoriais, entre os quais os ora denominados de Regiōes Produtivas Agrícolas. Em resumo: o agronegócio globalizado exerce papel fundamental para a expansão da urbanização e para a reestruturação urbana e regional, sendo a formação das RPAs um exemplo dessa reestruturação. É mesmo bastante visível no Brasil a existência de uma série de espaços urbanos não metropolitanos na confluência do padrão agrário atual, ajudando a soldar as RPAs.

Conforme tenho defendido (Elias, 2003a, 2006a, b, c, d, 2007a, b, 2008, 2009a, b, 2010), é possível identificar no Brasil agrícola moderno, seja nos espaços de reserva, seja nas áreas já há mais tempo inseridas na produção moderna, vários municípios cuja urbanização se deve diretamente à consecução e à expansão do agronegócio globalizado e cuja função principal claramente se associa às demandas produtivas dos setores relacionados à organização das redes agroindustriais.

Paralelamente à intensificação do capitalismo no campo com a difusão do agronegócio, processou-se um crescimento de áreas urbanizadas, porquanto, entre outras coisas, a gestão da agropecuária moderna necessita da sociabilidade e dos espaços urbanos. Tal fato colabora para o Brasil chegar ao século XXI com uma generalização do fenômeno da urbanização da sociedade e do território. Assim, ao lado da metropolização, principal característica da urbanização brasileira nas décadas de 1960 e 1970, Milton Santos (1993) advertia para o fato de o Brasil ter passado por verdadeira revolução urbana, a partir da década de 1980, com a expansão do fenômeno da involução metropolitana, quando crescem também as cidades médias e locais. Outros preferem usar os termos urbanização difusa, urbanização extensiva, e outros, ainda, cidade difusa e urbanização dispersa.

Sem dúvida, o impacto de todas essas transformações técnicas, econômicas e sociais na dinâmica populacional e na estrutura demográfica é intenso. Concomitantemente a uma verdadeira revolução tecnológica da produção agropecuária e agroindustrial e às 
transformações nas relações de trabalho, ocorreu uma revolução demográfica e urbana, marcada por grande crescimento populacional, particularmente nas cidades. Dessa forma, compreender como se processa a organização das RPAs contribui, também, para a compreensão de algumas das mais marcantes características e tendências da urbanização brasileira das últimas décadas.

Com a fluidez possível graças à construção dos sistemas de engenharia dos transportes e das comunicações que passam a se instalar nas áreas de difusão do agronegócio, intensificam-se as trocas de várias naturezas, muitas delas antes não existentes, com grandes impactos na vida social e no território, reformulando o sistema urbano antigo. A expansão das redes agroindustriais não apenas repercutiu na estrutura técnica das suas respectivas atividades econômicas como causou profundos reflexos nas relações de trabalho, transformando o conjunto de normas e padrões que as regulam. Como resultado, há uma nova divisão social e territorial do trabalho, com consequências na estrutura demográfica e do emprego, que também ajudam a melhor compreender o acelerado processo de urbanização, o qual se realiza sobre novas bases, e gera novas práticas socioespaciais.

Cada vez que o território brasileiro é reelaborado para atender à produção das redes agroindustriais, novos fixos artificiais se sobrepõem à natureza, e, desse modo, amplia-se a complexidade dos sistemas técnicos do espaço agrário. Diante disso, o território do agronegócio globalizado torna-se cada vez mais rígido, mais rugoso, promovendo uma urbanização corporativa (Santos, 1993; Elias, 2003a), empreendida sob o comando dos interesses das holdings hegemônicas do sistema agroalimentar.

Tudo isso fez da (re)estruturação urbana e regional fenômeno bastante complexo, dada a multiplicidade de variáveis que nela passam a interferir, como: a reestruturação produtiva da agropecuária; a organização das redes agroindustriais; a crescente especialização dessas produçôes; o crescimento da produção não material seja associado ao consumo produtivo do agronegócio ou ao consumo consultivo dos mais banais; o aumento da quantidade e da qualidade de trabalho intelectual associado ao agronegócio; o intenso processo de êxodo rural; a existência do agrícola não rural (trabalhador agrícola que mora na cidade); a migração descendente etc. É inviável, assim, considerar apenas as noções, conceitos e categorias que até então davam conta das análises na Geografia de maneira geral e, especialmente, na Geografia Agrária, Econômica, Urbana ou Regional e Economia Espacial.

\section{Cidades do Agronegócio}

Uma das consequências da reestruturação produtiva da agropecuária no Brasil é o processo acelerado de urbanização e crescimento urbano promovido, entre outras, pelas novas relações entre o campo e a cidade, desencadeadas pelas novas necessidades de consumo produtivo (Santos, 1988) das redes agroindustriais, as quais crescem mais rapidamente do que o consumo consultivo. Isso denota o que Santos (1988, 1993, 1994, 1996, 2000) chamou de cidade do campo, noção que utilizei por cerca de uma década (Elias, 2003a, b), embora, há alguns anos, a tenha substituído por cidade do agronegócio (Elias, 2006a, b, c, d, 2007a, b, 2008, 2009a, b, 2010), visando uma possível consolidação conceitual dessa ideia.

A utilização de tal noção vem causando algumas celeumas e precisa ser mais bem compreendida e, principalmente, estudada e debatida. O que chamo de cidades do agronegócio seriam os espaços urbanos inseridos em RPAs nos quais se dá a gestão local ou regional do agronegócio globalizado, que desempenham muitas novas funções urbanas, 
diretamente inerentes a esse. Transformam-se, então, em lugares de todas as formas de cooperação erigidas pelo agronegócio e resultam em muitas novas territorialidades. Se, como diz Carlos (2004), a cidade é a materialização das condições gerais de reprodução do capital, a cidade do agronegócio é aquela cujas funçôes de atendimento às demandas do agronegócio globalizado são hegemônicas sobre as demais funções, assim como de resto ocorre nas RPAs nas quais estão inseridas. Nessas, é nítida a dependência da economia urbana de alguma importante produção agrícola e/ou de sua transformação industrial.

Diria que a cidade do agronegócio é uma nova tipologia de cidade. Essa seria mais perceptível especialmente nos lugares de reserva recentemente inseridos à produção e ao consumo modernos, nos quais se realiza uma gama complexa de fluxos associados ao circuito superior da economia agrária. Seriam cidades em regiōes agrárias que vêm enriquecendo, que conhecem uma dinâmica econômica recente que gera nova riqueza. A cidade do agronegócio polariza amplo espaço agrário dinâmico, é um centro urbano que organiza esse espaço. Em outras palavras, a cidade do agronegócio está inserida em Regiōes Produtivas Agrícolas na confluência do agrário moderno com espaços urbanos não metropolitanos, e configura um lugar central de uma Região Produtiva Agrícola, parte integrante das redes agroindustriais, reflexo, meio e condição para o funcionamento dessas.

A especialização da cidade pode ser captada mediante a leitura de suas funçôes urbanas. Dado que as cidades do agronegócio apresentam uma especialização funcional, não basta a cidade estar inserida em uma RPA para poder ser classificada como uma cidade do agronegócio. O que a caracterizaria e a distinguiria de outro espaço urbano seria justamente uma hegemonia das funçóes inerentes às redes agroindustriais sobre as demais funções urbanas.

É possível identificar várias cidades, em diferentes partes do país, cuja existência, crescimento econômico e aumento da urbanização se devem diretamente à consecução do agronegócio globalizado: Luis Eduardo Magalhães (BA), Balsas (MA), Uruçuí (PI), Sorriso, Lucas do Rio Verde, Rondonópolis, Primavera do Leste (MT), Dourados (MS), Rio Verde (GO), Limoeiro do Norte (CE), Açu (RN), Petrolina (PE) e Juazeiro (BA), entre outras.

Algumas cidades que poderiam ser classificadas como do agronegócio são cidades refuncionalizadas com a difusão das redes agroindustriais. Mas outras se compõem de núcleos urbanos recentes. Entre esses últimos, alguns exemplos poderiam ser dados. Citaria a cidade de Luis Eduardo Magalhães, sede de município criado no ano de 2.000, a partir de desmembramento de Barreiras, conhecido como a capital do oeste baiano. Esse principal centro urbano dos cerrados nordestinos foi o primeiro a despontar com sua economia atrelada ao agronegócio da soja nesse bioma.

Luis Eduardo Magalhães é um dos lugares de reserva recentemente tomado pelas grandes empresas associadas às redes agroindustriais hegemônicas do complexo carnesgrãos (especialmente a multinacional Bunge Fertilizantes e Bunge Alimentos, instaladas na década de 1980).

Estudos realizados sobre a expansão da produção de grãos (principalmente soja, algodão e café) nos cerrados nordestinos, faz-me arriscar a dizer que o desmembramento de Luis Eduardo Magalhães, a cerca de mil quilômetros de Salvador, já é resultado da luta política desencadeada pelos grupos hegemônicos, reunindo capitais extra locais (pessoa jurídica e pessoa física), que se associam para buscar consolidar o próprio território, independente de outras forças políticas e econômicas locais, consideradas conservadoras pelos primeiros. 
Um visitante desavisado vai se surpreender ao chegar à cidade e se deparar com as grandes lojas de tratores, colheitadeiras, insumos químicos etc. que se perfilam pela entrada principal de Luis Eduardo Magalhães. O espanto continua quando, logo em seguida, o visitante se depara com as plantas industriais da Bunge, com seus portentosos silos, dentro do perímetro urbano da cidade, junto à área residencial.

A dinâmica populacional de Luis Eduardo serve de exemplo para seu dinamismo econômico, uma vez que o ritmo de seu crescimento populacional supera de longe a média nacional: seu contingente populacional somava cerca de 10 mil habitantes no ano de 2000, atingiu os cerca de 40 mil quatro anos mais tarde, e soma pouco mais de 50 mil nos dias atuais, cerca de dez anos após sua emancipação.

Outro exemplo da especialização funcional dessa cidade é que a mesma é uma das quatro cidades que recebem a Agrishow, ${ }^{13}$ Feira Internacional de Tecnologia Agrícola em Ação, um dos principais signos de feira comercial inerente ao agronegócio, sem dúvida uma das principais vitrines do que há de mais moderno para ser utilizado em toda a cadeia produtiva no agronegócio. A primeira versão local da feira ocorreu em 2004.

Para uma cidade do agronegócio, a mais importante característica é a especialização funcional. Por vezes, uma cidade que, inicialmente, pudesse ser classificada como do agronegócio, aumenta seu papel multifuncional com o crescimento, o que naturalmente faz com que a mesma perca uma das características principais das cidades do agronegócio. Isso não significa obrigatoriamente que o agronegócio deixe de ter importância econômica de determinada cidade ou Região Produtiva Agrícola, mas que outras atividades passam a ser determinantes estabelecendo-se novas dinâmicas socioeconômicas.

\section{PENSANDO A OPERACIONALIZAÇÃO DA PESQUISA SOBRE AS RPAS}

Como estratégia de ação, com vistas ao desenvolvimento de estudos e pesquisas sobre as Regiōes Produtivas Agrícolas, é fundamental selecionarmos alguns grupos de variáveis representativas para a realidade a ser estudada, tomando em conta o papel destas para a compreensão da produção das mencionadas regiōes. As ideias arroladas nesta seção resultam de um esforço empreendido no intuito de aperfeiçoar a metodologia para o estudo das áreas de organização das redes agroindustriais. ${ }^{14}$

Conforme entendo, a compreensão do âmago da produção do território das RPAs passa, necessariamente, pelo conhecimento empírico dos processos emergentes apresentados nas seçōes anteriores, da mesma forma que o contato direto com a realidade pesquisada contribui, indubitavelmente, para uma construção teórica mais consistente.

Nesse momento surge um ponto de inflexão importante. Se a revisão bibliográfica é tarefa difícil, o estudo do objeto a partir dessa é bem mais complexo, exige do pesquisador ou candidato a sê-lo, competência para operacionalizar a pesquisa, transpor a teoria para a prática, reconstruir o todo a partir do objeto.

No caso presente, a quantidade e complexidade dos campos teóricos exigidos para o estudo das RPAs, como já citado na introdução, é um agravante. O problema de conhecer e definir Regiôes Produtivas Agrícolas é o de saber o que são hoje; como evolui a liga regional produtiva ao longo do tempo; os abalos a essa liga regional, como resultado de processos produtivos novos e, finalmente, os novos arranjos territoriais resultantes. Nesse sentido, para apreender a realidade das RPAs teremos, necessariamente, de reconhecer o
13 As outras são Ribeirão Preto (SP), onde se iniciou a feira e onde ela apresenta versão de maior dinamismo; Rio Verde (GO) e Rondonópolis (MT).
14 Esta tarefa vem sendo particularmente implementada desde as pesquisas associadas à minha tese de doutorado e incrementada nos últimos anos. 
processo produtivo inerente às redes agroindustriais em sua evolução; o funcionamento da economia em nível mundial e seu rebatimento na formação econômica e social brasileira, com a devida compreensão da intermediação do Estado e do conjunto de agentes econômicos hegemônicos.

A chegada de novos agentes econômicos associados às redes agroindustriais, muitas vezes grupos de capital multinacional, requer a ampliação e modernização das infraestruturas e equipamentos que darão suporte ao desenvolvimento das atividades e ampliarão a fluidez espacial, no campo e na cidade, expandindo as redes de relaçóes nas quais se inserem as modernas regiōes agrícolas.

Há uma série de variáveis que são interdependentes e que devem fazer parte das preocupações para estudar as RPAs, porém foram privilegiados os aspectos que refletem mais fortemente as condiçóes da modernidade atual, aqui entendida como "[...] os processos e situações sociais que incorporem ou mostrem tendência a introduzir algo de novo, isto é, a inovar" (Sánchez, 1993, p.293).

A escolha de conduzir as análises tendo como pressupostos os temas e processos já citados nas seçôes anteriores somados às variáveis reunidas segundo eixos de operacionalização da pesquisa, a seguir mencionados, propiciarão: conhecer as dinâmicas de uso e ocupação do espaço agrícola; as dinâmicas de estruturação urbana dos espaços urbanos nelas inseridas e, ao mesmo tempo, compará-las entre si; avaliar os níveis diferentes de determinações decorrentes da atuação de novos agentes econômicos inerentes às redes agroindustriais; elaborar o pensamento com base não apenas em recortes territoriais, mas também a partir das articulações de diferentes unidades espaciais (escala geográfica), verificando os fluxos que articulam as RPAs, seja nos espaços agrícolas, seja nos espaços urbanos não metropolitanos. Dessa forma, devem ser levantados também dados relativos à presença ou não das infraestruturas e equipamentos associados às redes agroindustrias nas cidades e no campo, assim como dados sobre a dinâmica populacional e o mercado de trabalho etc.

Não será possível aqui abordar em profundidade todas as questôes inerentes à metodologia. Privilegiarei a apresentação dos eixos que sirvam para operacionalizar a pesquisa sobre uma RPA.

Parece-me importante, como norte metodológico, a escolha de variáveis com as quais seja possível reconhecer a especificidade atual da racionalização do espaço agrícola, das relações campo-cidade e a produção dos espaços urbanos não metropolitanos, assim como a reestruturação regional. Como estratégia de ação, julgo adequado agrupar algumas variáveis imprescindíveis para análise, segundo eixos, quais sejam: Eixo 1 - uso e ocupação do espaço agrário; Eixo 2 - ramos industriais representativos das redes agroindustriais; Eixo 3 - economia urbana; Eixo 4 - mercado de trabalho e dinâmica populacional; Eixo 5 - infraestrutura e equipamentos urbanos.

\section{CONSIDERAÇÕES FINAIS}

De acordo com o exposto, a partir das RPAs teríamos um recorte espacial para análise de algumas das mudanças ocorridas no território brasileiro, aumentando nossa capacidade de interpretar e de reconhecer os recortes atuais para melhor reconhecer o território. Uma vez que a globalização só se realiza com a fragmentação do território, a RPA ganha força como uma das possibilidades para percepção de tais processos. 
Estudar a Região Produtiva Agrícola significa, diante do citado, a possibilidade de apreender o conjunto das relações fundamentais que lhes dão os contornos duradouros em sua gênese e desenvolvimento, lembrando, porém: a outra "cara" do processo de análise é um processo de síntese, sendo essa "a visão de conjunto que permite ao homem descobrir a estrutura significativa da realidade com que se defronta, em uma situação dada. E é essa estrutura significativa que a visão de conjunto proporciona que é chamada de totalidade" (Konder, 1982, p.37).

Quando da eclosão do atual sistema temporal, que tem na globalização uma das suas principais marcas (Santos, 2000; Ianni, 1996; Hirst e Thompson, 1998), os espaços agrícolas se mostravam extremamente abertos à expansão dos sistemas de objetos e dos sistemas de ação (Santos, 1996) característicos do período. Portanto, os espaços agrários também se mecanizam e, onde a atividade agropecuária se dá baseada na utilização intensiva de capital, tecnologia e informação, principais forças produtivas do presente período histórico, é visível a expansão do meio técnico-científico-informacional (Santos, 1985, 1993, 1996, 2000), com o incremento da urbanização, do número e do tamanho das cidades e a organização de Regiōes Produtivas Agrícolas. Com a aceleração contemporânea (Santos, 1996) ou compressão tempo-espaço (Harvey, 1996), o campo apresentava-se como um espaço com menos rugosidades (Santos, 1985), possuidor de uma flexibilidade muito superior à apresentada pelas cidades e, assim sendo, como um lócus preferencial de expansão dos capitais industriais e financeiros.

Com a expansão dos sistemas de objetos voltados a dotar o território de fluidez para os investimentos produtivos, os fatores locacionais clássicos são redimensionados. Ocorre, assim, uma verdadeira dispersão espacial da produção, acirrando a divisão social e territorial do trabalho e as trocas intersetoriais, a resultar em diferentes arranjos territoriais produtivos agrícolas, entre os quais as Regiōes Produtivas Agrícolas em todo o país, compostas também por espaços urbanos, especialmente cidades locais e mesmo por cidades de porte médio.

Várias áreas foram plenamente incorporadas à produção, transformação e às trocas globalizadas de produtos agropecuários industrializados, ocupando um lugar privilegiado dentro da nova divisão do trabalho agropecuário e agroindustrial do Brasil, compondo nós ou manchas de modernas redes agroindustriais.

Podemos concluir ser impossível continuar simplesmente dividindo o Brasil entre urbano e rural. Os antigos esquemas adotados para classificar sua rede urbana, as divisões regionais encontram-se, em parte, ultrapassados. Requerem, portanto, urgente revisão capaz de dar conta da complexidade e da dinâmica da realidade atual. Uma das vias para essa revisão é, indubitavelmente, a compreensão de como se processa a (re)produção das Regiōes Produtivas Agrícolas. Essas são formadas seja por espaços agrícolas altamente racionalizados, seja por espaços urbanos não metropolitanos, cidades de porte médio e cidades menores. Avançar na compreensão das novas dinâmicas socioespaciais promovidas com a reestruturação produtiva da agropecuária encontra-se no âmago de qualquer análise destinada a melhor compreender as tendências da urbanização brasileira, das últimas quatro décadas de forma especial.

Compreender toda sorte de fluxos implicados nas RPAs, notadamente por meio das categorias de análise basilares representadas pelos circuitos espaciais de produção e dos círculos de cooperação, sobretudo os associados ao circuito superior da economia do agronegócio globalizado, é um exercício de análise. Tal exercício permite, de um lado, a síntese das estratégias de ação e processos inerentes às principais empresas associadas 
Denise Elias é professora adjunta do Programa de Pós Graduação em Geografia da UECE; coordenadora do grupo de pesquisa Globalização, Agricultura e Urbanização (GLOBAU); membro da Rede de Pesquisadores sobre Cidades Médias (ReCiMe); pesquisadora do CNPq.Email: deniselias@ uol.com.br

Artigo recebido em setembro de 2011 e aprovado para publicação em outubro de 2011. aos conglomerados atuantes no agronegócio e, de outro lado, a dinâmica do território resultante dessas estratégias, ou seja, das novas especializaçôes territoriais produtivas, evidenciando como se processam as dinâmicas territoriais inerentes ao setor. Logo, o estudo das Regiōes Produtivas Agrícolas compõe um dos caminhos possíveis de interpretação da produção do espaço de numerosas áreas do território brasileiro que têm em seu âmago a difusão do agronegócio e a organização das redes agroindustriais.

Como um dos objetivos maiores do presente texto é promover o debate do seu conteúdo e, especialmente, aperfeiçoar os caminhos possíveis para o estudo do território brasileiro do presente, em particular nas áreas de expansão das redes agroindustriais, ouso afirmar que a noção de Região Produtiva Agrícola compõe, um dos caminhos de conhecimento e interpretação da sociedade e do território brasileiros atuais.

\section{REFERÊNCIAS BIBLIOGRÁFICAS}

ELIAS, D. "Agronegócio e novas tendências da urbanização brasileira". Projeto de Pesquisa. Fortaleza: UECE, 2009a. 77 p. (apoiado pelo CNPq).

"Reestruturação produtiva da agropecuária e urbanização dispersa no Brasil”. In: SANFELIU, C. B.; SPOSITO, M. E. (Orgs.) Las ciudades medias o intermédias em um mundo globalizado. Lleida: Edicions de la Universitat de Lleida, 2009b. p.87-105. . "Redes agroindustriais e urbanização dispersa no Brasil". Scripta Nova (Barcelona), v. XII, p.74-96, 2008.

"O meio técnico-científico-informacional e a reorganização do espaço agrário nacional”. In: MARAFON, G. J.; RUA, J.; RIBEIRO, M. A. (Orgs.) Abordagens teórico-metodológicas em geografia agrária. $1^{\text {a }}$ ed. Rio de Janeiro: Ed. da UERJ, 2007 a. p.49-66.

"Agricultura e produção de espaços urbanos não metropolitanos: notas teórico-metodológicas". In: SPOSITO, M. E. (Org.) Cidades médias: espaços em transição. 1ª. ed. São Paulo: Expressão Popular (Coleção Geografia em Movimento), $2007 \mathrm{~b}$. . "Ensaios sobre os espaços agrícolas de exclusão". Revista NERA (UNESP), Presidente Prudente, São Paulo, v. 1, n. 8, p.29-51, 2006 a. Globalização e Agricultura. 1a. ed. São Paulo: EDUSP, 2003a. 401 p.

. "Globalização e fragmentação do espaço agrícola do Brasil". Scripta Nova. Barcelona / Espanha, v. 1, p.59-81, 2006b.

"Redes agroindustriais e produção do espaço urbano no Brasil agrícola". In: SILVA, J. B. S.; LIMA, C. L.; (Orgs.) Panorama da Geografia Brasileira. 1ª $^{\text {a }}$ ed. São Paulo: Annablume / ANPEGE, 2006c. p.221-38.

"Novas dinâmicas territoriais no Brasil agrícola". In: SPOSITO, E. S.; SPOSITO, M. E.; SOBARZO, O. (Orgs.) Cidades médias: produção do espaço urbano e regional. 1ª. ed. São Paulo: Expressão Popular, 2006d, v. 1, p.279-303.

. "Agricultura Científica no Brasil: impactos territoriais e sociais". In: SOUZA, M. A. A. (Org.) Território Brasileiro: usos e abusos. $1^{\text {a }}$. ed. Campinas: Territorial, 2003b. p.315-40.

ELIAS, D.; PEQUENO, R. "Mossoró: o novo espaço da produção globalizada e aprofundamento das desigualdades socioespaciais". In: SPOSITO, M. E; ELIAS, D.; SOARES, B. R. (Orgs.) Agentes Econômicos, reestruturação urbana e regional: Passo Fundo e Mossoró. São Paulo: Expressão Popular, 2010. 286 p. (série Cidades em Transição). p.101-283. 
. (Orgs.) Difusão do agronegócio e novas dinâmicas socioespaciais. 1a ed. Fortaleza: BNB, 2006. 483 p.

HARVEY, D. Condição pós-moderna. 6a ed. São Paulo: Edições Loyola, 1996.

HIRST, P.; THOMPSON, G. Globalização em questão. A economia internacional e as possibilidades de governabilidade. Petrópolis: Vozes, 1998.

IANNI, O. Teorias da globalização. $3^{a}$ ed. Rio de Janeiro: Civilização Brasileira, 1996.

SANTOS, M. A natureza do espaço. São Paulo: Hucitec, 1996. . A Urbanização Brasileira. São Paulo: Hucitec, 1993. . Espaço e Método. São Paulo: Nobel, 1985. . Metamorfoses do Espaço Habitado. São Paulo: Hucitec, 1988. . Por uma outra globalização. Rio de Janeiro: Record, 2000. . Técnica, Espaco, Tempo. São Paulo: Editora Hucitec, 1994.

A B S T R A C T The changes in the agricultural activity in the last five decades have profound impacts on the (re) organization of the Brazilian territory, resulting in new territorial arrangements. Among them, we highlight those related to agribusiness globalized areas chosen to receive the most significant productive investments in the sector, that represent its most competitive areas, which we are calling Productive Agricultural Regions (RPA). The main objectives of this paper are: to discuss the concept of Productive Agricultural Region $(R P A)$; to present evidences for the identification and characterization of the mentioned region; to improve the analytical path that has been trodden in the context of geographic studies, in order to consolidate this conceptual idea.

K E Y W O R D S Agribusiness; disperse urbanization; urban and regional restructuring. 